\title{
Continuity and Context
}

\author{
William Buskist \\ M. Christopher Newland \\ Thomas Sherburne \\ Auburn University
}

The desideratum of the experimental analysis of behavior can be summarized simply-to explain the relationships among behavior and its controlling variables. This task was inaugurated in 1938 when Skinner published his Behavior of Organisms. Since then, thousands of operant experiments and classroom/laboratory demonstrations using nonhuman animal subjects have testified to the power of the contingencies of reinforcement in controlling behavior (e.g., Ferster \& Skinner, 1957). Indeed, the basic principles of shaping, reinforcement, punishment, and extinction were each discovered by carefully observing rats pressing levers and pigeons pecking translucent disks in highly controlled laboratory environments.

Baron, Perone, and Galizio now pose the question of whether these principles can explain human behavior. As they correctly point out, this old question originates in Skinner's conceptual analyses of human behavior (e.g., Skinner, 1953, 1957), although he never attempted to answer it empirically. Those who have, though, have found that their results often do not resemble those typical of nonhuman animal experiments (for a review, see Baron \& Galizio, 1983; Davey \& Cullen, 1988; Weiner, 1983). Such discrepancies have led many to charge either that the three-term contingency is not adequate in explaining human behavior or that human action is simply too complex to be studied in the operant laboratory. These claims are quickly and deftly countered by Baron et al., who argue that correct applications of tradition-

We wish to thank Dr. Rick Flemming and Dr. Irwin Rosenfarb for reading and commenting on earlier versions of this manuscript.

Address reprint requests to either the first or second author, Psychology Department, Auburn University, Alabama 36849-5214. al steady state operant procedures will yield the sorts of experimental control over human behavior necessary to answer the question they pose.

We agree with Baron and his colleagues that the only way to understand human behavior is to subject it to a proper and thoroughgoing experimental analysis. We also agree that apparent discrepancies between the behavior of human and nonhuman animals under similar reinforcement contingencies are not sufficient reason for abandoning laboratory research with humans. We wish to amplify two important points that Baron et al. offered in defending their position and add a point of our own to their discussion. First, the view that humans are fundamentally different from nonhumans fuels the argument that the laws that govern human behavior must be different from those that govern nonhuman animal behavior. This position ignores the work of Darwin and evolutionary biologists to our understanding of life. Second, operant researchers have largely ignored the contributions of extra-experimental contingencies to human laboratory performance. Failure to consider the milieu in which human operant research is conducted ignores a powerful set of variables that likely interacts with experimental contingencies in determining within-session behavior. Third, the traditional "human Skinner box" is insufficient to study the social variables of which so much of our behavior is a function. Each of these points is addressed below.

\section{CONTINUITY OR DISCONTINUITY OF SPECIES?}

The basic principles of reinforcement have been demonstrated in every mammal and bird on which they have been 
studied and have been replicated in fish, octopi, and crabs (Abramson \& Feinman, 1987; Dews, 1959; Marcucella \& Abramson, 1978). Other observations, such as "schedule-typical" patterns of responding, have more limited applicability: they have only been identified in every bird and nonhuman mammal studied. Such interspecies generality is truly impressive and unusual in psychology. Therefore, when a single species behaving under poorly controlled conditions fails to respond as other species do under more highly controlled conditions, we should be extremely reluctant to attribute uniqueness to that species, even if it is human.

The willingness to reject a corpus of research findings from the animal laboratory is especially puzzling when viewed against an eagerness among many experimental psychologists (and some behavior analysts) to accept computer models of behavior. Just as we should be reluctant to ignore principles derived from the study of animals, we should also temper our enthusiasm for silicon-based devices that do not even demonstrate patterns of responding seen in carbon-based species! For example, not even neural networks have emitted the rich subtleties of fixedinterval responding so eloquently described by Gentry and his colleagues (Gentry, Weiss, \& Laties, 1983).

The challenge that schedule-typical behavior appears in humans (or computer models) might be confused with a challenge that more fundamental principles of conditioning appear. The two challenges should be distinguished. The FI pattern of responding is not a principle but is probably a confluence of principles that are manifested in ways that are now dimly understood. That FI behavior patterns sometimes fail to appear in humans is not grounds to disregard a huge and impressive animal literature when regarding human behavior. However, such failures are grounds for investigating this fascinating schedule further. If more basic principles, such as the three-term contingency, do not appear to control human behavior, then, and only then, should we become very concerned.
How are we to make sense of those discrepancies that exist between human and nonhuman animal behavior? One strategy is to make the conditions under which the investigation of humans is conducted more like those involved in experiments with other animals. Using this strategy, an investigator would introduce to human experiments the same rigor and care that has contributed to the discovery of the principles of behavior with nonhuman animal subjects. Baron and his colleagues make an impressive case for this strategy.

An alternative strategy to reproducing the precise behavior control present in experiments with nonhumans might be to study with nonhumans those difficulties that plague human experimentation. As Baron et al. point out, these "problems" may represent important variables. If one thinks that the problem is that the baseline is too short and unstable, then experimentally analyze the role of the stability of the baseline and the time spent on it with both kinds of subjects. If programmed consequences do not adequately compete with uncontrolled extra-experimental contingencies, then experimentally analyze similar settings using nonhuman subjects. If humans do not display FI-like behavior because of the presence of a clock (or the opportunity to count seconds) or because of a long and varied history in which speed of responding is important, then subject these variables to experimental analysis into the nonhuman laboratory.

Thus, two experimental strategies might be described. One might be summed up as "Identify those conditions under which humans behave like other animals." The other might be summarized as "Identify those conditions under which other animals behave like humans." Both should be useful in isolating those variables that control behavior, and in revealing actual discrepancies. A simple and widely known example illustrates the second strategy. FI schedules sometimes maintain very low response rates in humans, and this might be regarded as specific to human FI performance (but see Newland \& Weiss, 1990, for such a 
pattern in a cebus monkey). In humans these low rates have been attributed to the role of a "clock" controlling subjects' behavior (e.g., Lowe, 1979). Such a clock could be public, such as watch, or private, such as counting. However, this reasonable explanation is not limited to humans, it could be applied to other species (Ferster \& Skinner, 1957; Laties \& Weiss, 1966).

There are important questions to be asked about human behavior. But often these questions are preceded by querying whether the principles of behavior discovered with nonhuman species are even pertinent to human behavior, as was pointed out by Baron et al. This is an indictment of our science. The authors are not to be faulted for asking the question; they are under appropriate control of their audience. But consider the implications of such a query. Do humans emit behavior that is not operant? Is the three-term contingency irrelevant to human behavior? There are "comprehensive accounts" of human behavior that ignore the immense data base found in the nonhuman animal literature. The list is too long to describe here, but as an example, try to locate references to Reynolds' (1961) powerful account of "attention" in the massive cognitive literature on that topic. That psychologists can maintain, and sometimes even boast of, ignorance of the nonhuman animal literature is scandalous because it neglects a sound empirical literature and sets humans apart from other members of the animal kingdom. We see no reason, at least presently, to claim that human behavior is qualitatively different, in either its origins or function, from that of other animals.

\section{IMPORTANCE OF EXTRA-EXPERIMENTAL CONTINGENCIES AND SOCIAL BEHAVIOR}

In some respects comparing human and nonhuman performance under schedules of reinforcement might be misleading. While evolutionary continuity across species suggests that human and non- human behavior might be similar under similar conditions, an examination of environmental variables could lead to different conclusions. A species' evolution does not occur independently of its ecological niche. Simply put, the context in which humans and nonhumans live and participate in operant experiments varies considerably. Most human operant research ignores the role of extra-experimental differences in controlling withinsession behavior of their subjects, and most researchers who use nonhuman animals do everything they can to eliminate or control these differences. Consider the behavior of a rat and a human under the same schedule of positive reinforcement in their respective operant chambers. The rat is likely to be food-deprived and its behavior results in the delivery of food. The human is not similarly deprived of the reinforcer serving as the consequence for responding (most likely either points on a computer screen or points exchangeable for relatively small amounts of money). Different states of deprivation are likely to exert powerful control over the behavior of both species, even under similar schedules (e.g., Dardano, 1973; see also Skinner, 1953).

The significance of the reinforcer for the behaving organism must influence behavior in the experiment. For rats, behaving in the operant chamber produces the food necessary for its survival (although outside the experiment it is likely to be fed enough to maintain its reduced weight). For humans, behaving in the operant chamber satisfies a course requirement, earns extra credit, or a few bucks for pizza and beer. Human subjects in our laboratory have been known to complain of boredom; on two occasions, we have even found subjects asleep in the operant chamber! Clearly, the extra-experimental variables controlling human responding are different from those controlling nonhuman responding. Perhaps an example will make this point clearer.

Several years ago, one of us (WB) conducted an experiment in which peanuts were delivered to humans according to a FI 27 s schedule. One subject always responded at a very low rate, about one 
response per reinforcer. Then, one day, she produced a scalloped response pattern that resembled that of a rat on an intermediate FI schedule. On the next day, though, her responding reverted to its typical low rate. When the study was over, I asked her why she responded differently on that one day. She told me that she had to hurry to an appointment immediately after the session, and that by responding "faster about half-way through the time between peanuts, she could produce them quicker." This led to the idea that perhaps instructions could be used to simulate different kinds of extra-experimental conditions that could potentially affect a subject's within-session behavior. H. L. Miller and I designed an experiment to investigate this possibility and found that subjects' behavior could be powerfully altered by such instructions (Buskist \& Miller, 1981).

Such extra-experimental variables are likely to modulate the control that within-session reinforcers exert over human behavior. In many human operant experiments, we cannot be sure that the programmed consequences are indeed reinforcers (cf. Galizio \& Buskist, 1988). For that reason alone, studies of reinforcement schedules with humans, particularly those that clearly show the reinforcing properties of programmed consequences, are necessary and should be welcomed. Selecting reinforcement procedures and arranging experimental contingencies with humans cannot be based on analogous procedures used with nonhuman animal subjects because too many extra-experimental factors mitigate against the effectiveness of withinsession reinforcers. Instead of attempting to eliminate or control such variables, they should be isolated and studied systematically.

Much, if not most, human behavior is under the control of socially-mediated reinforcement (as is nonhuman primate behavior), and the science of behavior will be incomplete until the variables that govern social interactions are studied thoroughly. Studying one individual as he or she responds independently of others, regardless of the rigor of the meth- odology, is unlikely to provide an adequate account of social influence. So far, though, relatively few behavior-analytic studies of social behavior have been conducted (e.g., Buskist \& Morgan, 1987; Hake, Vukelich, \& Olvera, 1975; PefferSmith, Smith, \& Byrd, 1983; Schmitt, 1976). The reason for this appears twofold. First, experimental analysts study behavior the way they do because they have been trained to study repetitive and easily emitted behavior. But such behavior is not representative of the dynamic nature of social action. While evolutionary and operant principles of selection are present in both leverpressing and social interactions, the particulars are likely to be very different. It is in these particulars that important principles may lie.

Second, the standard operant chamber does not lend itself easily to studying the codependent behavior of two or more organisms, although some sorts of social interaction can be studied with appropriate modifications of the chamber, such as linking two chambers together (e.g., Buskist \& Morgan, 1987). An infatuation with the operant chamber may exert undue influence on our view of behavior and its causes. If behavior is of the type that cannot be studied easily in the operant chamber, as is much human social behavior, it too often goes unstudied, and we can only speculate about its controlling variables (usually by merely renaming it and its context with behavioral terms). As Baron and his colleagues suggest, such linguistic sleight of hand contributes little to our understanding of behavior.

We are confident that our principles are adequate to the task of explaining human action; but the medium in which we study human action is inadequate to show us how those principles do, in fact, operate. What is badly needed is an alternative to the standard operant chamber and clever modifications of it for studying human action. Until such innovations are created and tested, we are likely to remain ignorant of many determinants of our behavior.

The strategic shift suggested above may help uncover such determinants. But we 
should also not overlook the contributions of applied research and nonmanipulative procedures as a starting point for considering how to study human behavior. One way to understand human action is to observe it systematically under natural conditions. Investigators could analyze conditional probabilities among environmental events and individual behavior patterns. More careful observation as it occurs in situ may lead to insightful speculations that can then be brought into the laboratory for closer and more controlled scrutiny. Surely, this approach would be more efficient than merely speculating about the variables governing human action. (Speculation is a poor practice only when substituted for experimental analysis.)

\section{CONCLUSIONS}

We agree with Baron, Perone, and Galizio that the discrepancy between animal and human behavior under schedules of reinforcement is not a valid reason for abandoning the laboratory study of human behavior or for excluding the results from animal studies in developing a theory of human action. That humans do not always perform the same way as nonhuman animals also does not suggest that behavioral principles do not hold for human behavior. The discrepancies do recommend, though, the need for a more thoroughgoing analysis of human behavior.

As Baron et al. suggest, such analysis should find its roots in the traditional steady state methodology that has been so successful in the study of nonhuman animal behavior. We suggest that additional methods may also benefit our understanding of human behavior. One approach might be to attempt to produce human-like behavior in animals by reproducing conditions in animal experiments that seem problematic in human experiments. We also suggest that the operant chamber itself has limited the creativity of researchers in their quest to understand human action. The operant chamber has been and will continue to be a useful medium in which to study behavior, but modifications of it appear necessary to study the broad range of human action. We suggest that new and creative innovations in method are needed for the study of human action. The work of Bernstein and Ebbesen (1978), Hake and his colleagues (e.g., Hake et al., 1975), Schmitt (1976), and Buskist and Morgan (1987) provide promising starting points from which even more innovative approaches to studying human behavior may be derived.

Baron et al. are correct in calling for more thorough experimental analyses of human behavior. Speculation alone is insufficient. Empirical work must be accomplished and Baron et al.'s call is testimony to the appreciation of the powerful principles of behavior that have been discovered in research with nonhuman animals. It would be truly astonishing if these principles did not hold for humans, too. It would be even more astonishing if new principles that applied to the behavior of all animal species were not discovered. We are still relatively new at studying behavior and have much to learn. We need to continue to study it carefully, creatively, and with the most efficient methods.

\section{REFERENCES}

Abramson, C. I., \& Feinman, R. D. (1987). Operant punishment of eye movement in the green crab, Carcinus maenas. Behavioral and Neural Biology, 48, 259-277.

Baron, A., \& Galizio, M. (1983). Instructional control of human operant behavior. The Psychological Record, 33, 495-520.

Bernstein, D., \& Ebbesen, E. (1978). Reinforcement and substitution in humans: A multi-response analysis. Journal of the Experimental Analysis of Behavior, 30, 243-253.

Buskist, W., \& Miller, H. L. (1981). Effects of instructional constraints on human fixed-interval performance. Journal of the Experimental Analysis of Behavior, 35, 217-225.

Buskist, W., \& Morgan, D. (1987). Competitive fixed-interval performance in humans. Journal of the Experimental Analysis of Behavior, 47, 145158.

Dardano, J. F. (1973). Self-imposed time outs under increasing response requirements. Journal of the Experimental Analysis of Behavior, 19, 269287.

Davey, G., \& Cullen, C. (Eds.). (1988). Human operant conditioning and behavior modification. New York: Wiley.

Dews, P. B. (1959). Some observations of an op- 
erant in an octopus. Journal of the Experimental Analysis of Behavior, 2, 57-64.

Ferster, C. B., \& Skinner, B. F. (1957). Schedules of reinforcement. New York: Appleton-CenturyCrofts.

Galizio, M., \& Buskist, W. (1988). Laboratory lore and research practices in the experimental analysis of human behavior: Selecting reinforcers and arranging contingencies. The Behavior Analyst, 11, 65-70.

Gentry, G. D., Weiss, B., \& Laties, V. G. (1983). The microanalysis of fixed-interval responding. Journal of the Experimental Analysis of Behavior, 39, 327-344.

Hake, D. F., Vukelich, R., \& Olvera, D. (1975). The measurement of sharing and cooperation as equity effects and some relationships between them. Journal of the Experimental Analysis of Behavior, 23, 63-79.

Laties, V. G., \& Weiss, B. (1966). The influence of drugs on behavior controlled by internal and external stimuli. Journal of Pharmacology and Experimental Therapeutics, 152, 388-396.

Lowe, C. F. (1979). Determinants of human operant behavior. In M. D. Zeiler \& P. Harzem (Eds.), Advances in the analysis of behaviour: Vol. 1. Reinforcement and the organization of behavior (pp. 159-192). New York: Wiley.

Marcucella, H., \& Abramson, C. I. (1978). Be- havioral toxicology and teleost fish. In D. I. Mostofsky (Ed.), The behavior of fish and other aquatic life (pp. 33-77). New York: Academic Press.

Newland, M. C., \& Weiss, B. (1990). Drug effects on an effortful operant: Pentobarbital and amphetamine. Pharmacology, Biochemistry, and Behavior, 36, 381-387.

Peffer-Smith, P. G., Smith, E. O., \& Byrd, L. D. (1983). Effects of d-amphetamine on self-aggression and posturing in the stumptail macaque. Journal of the Experimental Analysis of Behavior, 40, 313-320.

Reynolds, G. S. (1961). Attention in the pigeon. Journal of the Experimental Analysis of Behavior, 4, 203-208.

Schmitt, D. R. (1976). Some conditions affect the choice to cooperate or compete. Journal of the Experimental Analysis of Behavior, 25, 165-178.

Skinner, B. F. (1938). Behavior of organisms. New York: Appleton-Century-Crofts.

Skinner, B. F. (1953). Science and human behavior. New York: Macmillan.

Skinner, B. F. (1957). Verbal behavior. Englewood Cliffs, NJ: Prentice-Hall.

Weiner, H. (1983). Some thoughts on discrepant human-animal performances under schedules of reinforcement. The Psychological Record, 33, 521532. 